\title{
Percepciones geográficas de El Greco. Vista y plano de Toledo
}

\section{Vista Y PLANO DE TOLEDO}

En el año 2014 se celebró el IV centenario de la muerte de El Greco con múltiples eventos y conmemoraciones. Al hilo de tal onomástica se analiza la capacidad de El Greco de representar el territorio de forma verosímil y rigurosa según la forma imperante en el siglo xVI. La metodología empleada se apoya en herramientas SIG y se contextualiza con una serie de encargos que realizó Felipe II y su relación con el cuadro Vista y plano de Toledo, uno de los cuadros más conocidos del pintor cretense. Se trata de una vista panorámica, en lienzo de gran formato y pintado al final de su vida, en torno a la segunda década del siglo XviI. Se interpreta que podría haber sido un encargo del coleccionista de mapas Pedro Salazar de Mendoza. Así aparece reflejado en su inventario de 1629 como propietario, siendo citada la obra como «Quadro de Toledo con su planta» ${ }^{1}$. Don Pedro Salazar era el administrador del Hospital de San Juan Bautista, también conocido de Tavera por el Arzobispo Juan Pardo de Tavera.

El cuadro está pintado desde una posición al norte de la ciudad, mirando hacia el sur en el denominado Cerro de la Horca, junto al cementerio hebreo abandonado y lugar del actual camposanto de la ciudad. La representación de los lugares y edificios de la ciudad es muy precisa. Aparece cual fotografía con un mayor enfoque o detalle en las pinceladas de la zona central del cuadro lo que permite distinguir y reconocer muchos de las arquitecturas de la ciudad. A medida que nos alejamos en los extremos del cuadro, los volúmenes se difuminan a través de las pinceladas mucho más sueltas, como puede verse en los arrabales de la vega del Tajo.

${ }^{1}$ Calduch, J. (2011): "El Greco. Pintor de mapas". Al detalle. Museo del Greco. http://museodelgreco.mcu.es/web/docs/boletin11.pdf (Verificada: 22/9/2015). 
La vista de la ciudad de Toledo aparece en el fondo del cuadro, en un segundo plano. La estructura triangular del cuadro que antecede a la vista se halla conformada por tres elementos, cada uno de ellos ubicados en el vértice de un triángulo imaginario con el Hospital de Tavera al medio. En la zona central superior, sobre el cielo de la ciudad y sobre el vértice del campanario de la catedral, desciende un grupo celestial presidido por la virgen para imponer la casulla a San Ildefonso, patrono de Toledo. En la parte inferior izquierda, cercano al dibujo del río y al Puente de Alcántara, se ubica una figura dorada con los símbolos de la abundancia, como el cántaro desde el que mana agua, acompañado de diversos frutos. Se trata de una alegoría del río Tajo. Por último, en la parte de la izquierda, se ubica un joven que sostiene un plano de la ciudad de Toledo con toda una serie de anotaciones.

El Greco, no era ajeno a conocimientos cartográficos por su extensa formación renacentista ${ }^{2}$. Además, Candia su ciudad natal y colonia veneciana, estaba fortificándose en tiempos de la juventud de El Greco. Se cree que pudo aprender técnicas de levantamientos topográficos con un cartógrafo cretense Síderis con el que trabajó antes de marchar a Venecia ${ }^{3}$. Otra posibilidad es que su hijo, muchacho representado en el cuadro sosteniendo dicho mapa, fuera el que le ayudara a realizarlo por su formación como arquitecto. Ello nos hace intuir en la rigurosidad de la representación de la ciudad de Toledo, incluido el plano. Además, en muchas de las obras de El Greco, se combina una carga religiosa con la difusión de la ideología humanística, propia del Renacimiento. Sus cuadros suelen tener un doble mensaje que combina ideales manieristas y neoplatónicos con el espíritu de Trento, dirigido tanto a fieles como a eruditos ${ }^{4}$.

El estudio se centra, más allá de la faceta artística y religiosa que hemos vislumbrado en la descripción del cuadro, en la componente territorial y geográfica. Los elementos icónicos y reconocibles del cuadro son analizados y verificados con la vista de la ciudad de Toledo actual, a través de herramientas SIG. Se completa el análisis con una georreferenciación del mapa con la cartografía actual. Estos elementos que describen y presentan la ciudad de Toledo son equiparables a proyectos de conocimiento territorial, propios del siglo XVI, y que entre otros el monarca Felipe II, solicitó para tener un sólido conocimiento de sus dominios tanto en la península como en ultramar.

2 http://www.abc.es/local-toledo/20130204/abci-biblioteca-greco-201302041414.html (Verificada: $22 / 9 / 2015)$.

${ }^{3}$ Calduch, J. (2012): "El Greco cartógrafo: Vista y plano de Toledo (1608-1614)". EGA. Revista de Expresión Gráfica Arquitectónica, 19, pp. 68-77.

${ }^{4}$ Martín González, J. J. (1986): Historia del Arte. Madrid, Ed. Gredos, vol. II. 


\section{LA CARTOGRAFÍA Y FELIPE II}

El interés de Felipe II por la Geografía y ciencias afines está más que contrastado y se manifiesta en diversos proyectos que solicitó durante su reinado. Este gusto viene heredado de su padre, el emperador Carlos V y de las tendencias que recorren Europa tras el descubrimiento del nuevo mundo. Estas decisiones de Felipe II se inspiraron en la Cosmografía Ptolemaica presentado en el libro de Cosmografía de Pedro Apiano ${ }^{5}$. El método ptolemaico fundamenta las bases de una descripción correcta de la superficie terrestre. Distingue para ello dos disciplinas: la «Geografía» o «representación gráfica de todo el mundo conocido junto con los fenómenos contenidos en él» y la «Corografía» ${ }^{6}$ «descripción los menores detalles de los lugares». La Geografía se ocupa de las regiones y la representación de sus rasgos: Por ello, es fundamental la geometría y la cartografía. Por contra, la corografía se ocupa de los detalles, de pintar los lugares que describe. En este caso, es fundamental un artista, un pintor $^{7}$. Esta idea se mantiene en el tiempo con la «Scenografia» (perspectiva) e «Ichnografia» 8 (planta) del dibujo arquitectónico definido por Vitrubio.

Fueron múltiples los encargos relacionados con la cartografía y corografía que se desarrollaron en el siglo XVI a petición de los monarcas. Queremos destacar tres proyectos cuya finalidad era el conocimiento de las tierras peninsulares y que en su concepción guardan relación con el análisis del cuadro.

- Mapas. Son varios los proyectos iniciados e inconclusos. Destaca de todos ellos el Atlas de El Escorial. Es el primero de los encargos importantes en la relación del monarca con la Geografía. Proyectado por su padre Carlos V se encomendó, según algunos al Maestro Pedro de Esquivel,

${ }^{5}$ Apiano. Profesor de Carlos V y cuyo libro fue regalado a Felipe II entre otros de Geografía, en 1545.

${ }^{6}$ «Chorografía es la misma cosa que topografía, la cual se puede decir traza de lugar, describe y considera particulares lugares por si aparte, sin consideración ni comparación de sí mismos, ni dellos con otros. Empero con una gran diligencia considera todas las particularidades y propiedades, por mínimas que sean que en los tales lugares se hallan dignas de notar, como son puertos, lugares, pueblos, vertientes de ríos y todas las cosas semejantes: como son los edificios, casas, torres, murallas y cosas tales. El fin de la chrorografia es pintar un lugar particular, como si un pintor pintase una oreja, o un ojo y otras partes de la cabeza de un hombre» http://weblioteca.uv.es/cgi/view.pl?source=uv_im_il5607197 (Verificada: 22/9/2015).

${ }^{7}$ Kagan, R. L. (1986): "Felipe II y los geógrafos", en R. L. Kagan, (coord.): Ciudades del siglo de Oro. Las vistas españolas de Anton Van den Wyngaerde. Madrid, Ed. El viso, pp. 41-53.

8 Cap. 2 Libro 1, Vitrubio, Los Diez Libros de Arquitectura Marco Lucio Vitruvio Polion http://www.estucos.es/bibliografia/Vitrubio.pdf (Verificada: 22/9/2015). 
profesor de matemáticas de la Universidad de Alcalá ${ }^{\text {y }}$ según otros a Alonso de Santa Cruz cosmógrafo al servicio Real ${ }^{10}$. Ambos autores realizaron diversos proyectos cartográficos. Este Atlas es la primera representación a escala de la península ibérica y se tardarán siglos hasta tener algo similar con el mapa de Tomás López ${ }^{11}$.

- Textos. Listados sobre información del territorio. En el siglo XVI aparecen los denominados repertorios entre los que destacan Villuga, Meneses, y las ya, más completas, Relaciones Topográficas encargadas por Felipe II en 1574. Cuestionario enviado a todos los pueblos de España pidiendo información sobre su geografía, economía, población,... a semejanza de las Relaciones del Nuevo mundo ${ }^{12}$. Estas relaciones textuales e indexadas buscaban una descripción completa histórica y topográfica de España, a modo de inventario.

- Vistas. Es el tercero de los encargos cronológicamente hablando y el más próximo a nuestro objeto de estudio. Anton Van den Wyngaerde, pintor holandés, realizó una serie de imágenes de ciudades de la geografía española. Además de tener un gran valor artístico, cuentan con importantes valores históricos y por supuesto geográficos ${ }^{13}$. En su método de trabajo, el pintor realizaba un borrador de menores dimensiones. Posteriormente, y a través de una cuadrícula lo trasladaba al tamaño ya definitivo. Ejemplo de ello es la vista de Cuenca. El boceto mide 172x595 mm y la versión definitiva mide 420X1418 teniendo los mismos elementos representados y el mismo número de cuadrados en la cuadrícula. Es interesante reseñar que en el dibujo acabado, la retícula está superpuesta al dibujo mientras que en el boceto de línea pequeño, el papel ya tenía dibujada la retícula a pluma y tinta antes de pintar el dibujo ${ }^{14}$.

\footnotetext{
${ }^{9}$ Morato, M. (2012): "Representación del territorio en la cartografía regional renacentista: algunos ejemplos". Boletín de la Asociación de Geógrafos Españoles, 59, pp. 25-48.

${ }^{10}$ Martín, J. (2002): Historia de la Cartografía y la Topografía. Madrid, Centro Nacional de Información Geográfica.

${ }^{11}$ http://www.rah.es/pdf/Indice_Mapas.pdf (Verificada: 22/9/2015).

12 Pereda, F. y Marías, F. (2002): El Atlas del Rey Planeta: La descripción de España y de las Costas y Puertos de sus reinos. Madrid, Nerea.

13 Caballero, M. A. (2008): "Las vistas de El Puerto de Santa María de Wyngaerde". Revista de Historia de El Puerto, 41/2 semestre, pp. 109-147.

${ }^{14}$ Haverkamp-Begemann, E. (1986): "Las vistas de España de Anton Van den Wyngaerde", en R. L. Kagan (coord.): Ciudades del siglo de Oro. Las vistas españolas de Anton Van den Wyngaerde. Madrid, Ed. El viso, pp.55-67.
} 


\section{ANÁLISIS COMPARADO}

Se ha hecho una comparación visual del cuadro con las diferentes visiones que ofrecen diversas herramientas SIG. Esta recreación permite deambular desde múltiples perspectivas e incluso ubicarse en el supuesto mismo lugar donde podría haberse situado el pintor. Permite llegar a una comprensión mucho más holística del territorio representado ${ }^{15}$.

\section{FIGURA 1}

ANÁLISIS DE VISTA Y PLANO DE TOLEDO

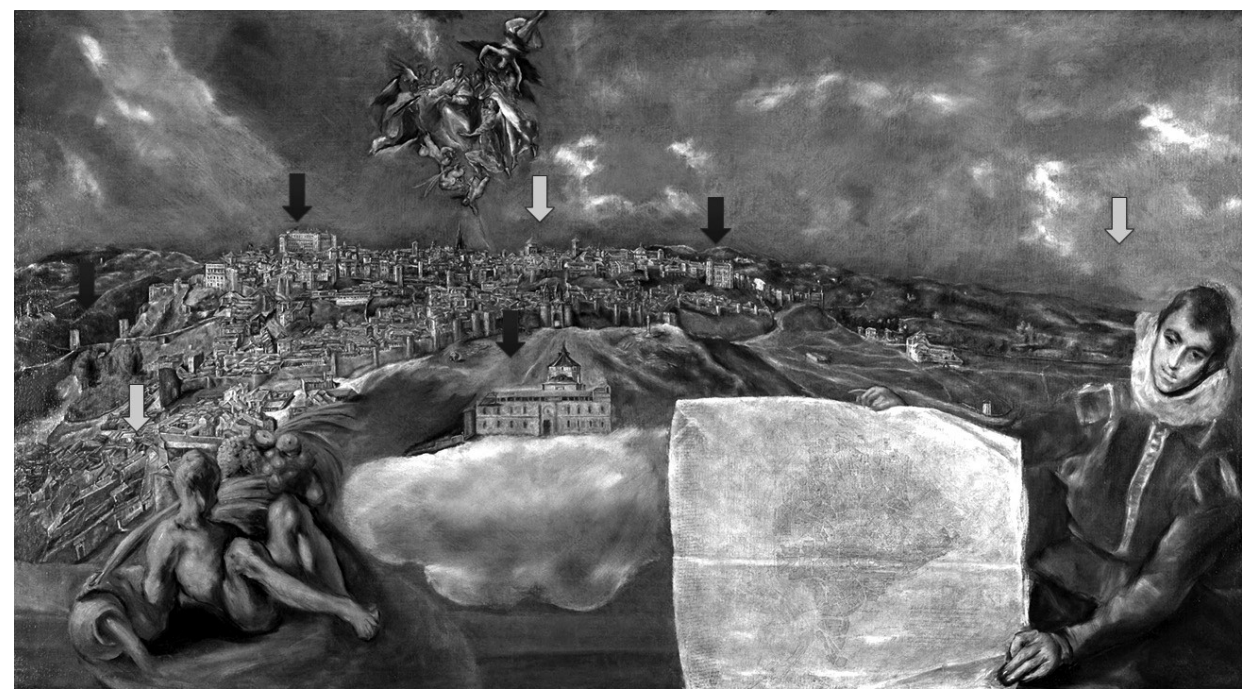

Fuente: Elaboración propia.

Se aprecian elementos icónicos de la ciudad que han perdurado en los siglos y sirven, cual puntos de control, como elementos de relación. Se percibe una clara reducción del relieve. El «skyline» de la ciudad se apoya sobre la zona de los Cigarrales, mientras que en el cuadro perfila directamente sobre el horizonte.

15 http://es.slideshare.net/JuanAntonioGarciaGonzlez/plano-y-vista-de-toledo-aproximacingeogrfica (Verificada: 22/9/2015). 
FIGURA 2

ANÁLISIS DE VISTA Y PLANO DE TOLEDO

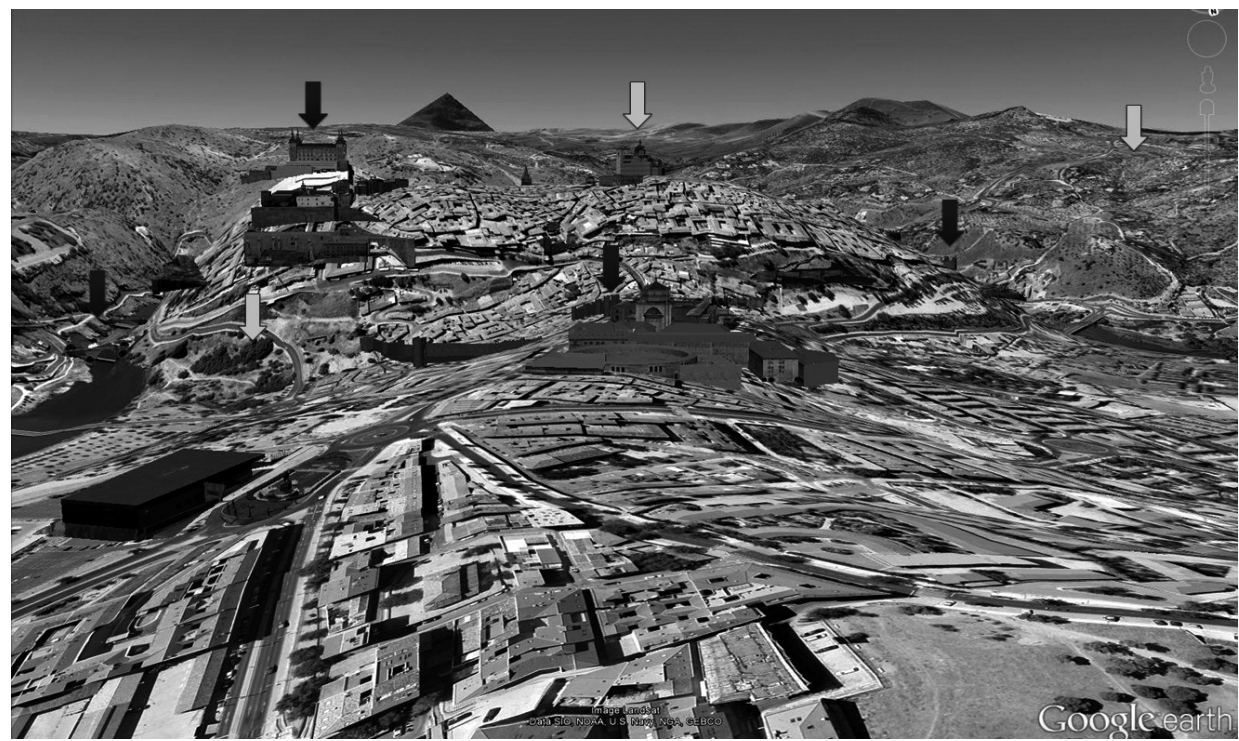

Fuente: elaboración propia.

Destaca el Puente de Alcántara, flanqueado por el Alcázar y el Castillo de San Servando a uno y otro lado. Aparecen representadas dos torres de corte defensivo a ambos lados del puente que con posterioridad una de ellas fue sustituida por una puerta barroca. El Alcázar se halla en la parte más elevada del cerro y presenta notables diferencias con el actual. El dibujado por El Greco fue obra de Alonso de Covarrubias en el reinado de Carlos I y se halla en el mismo lugar que ocupa hoy en día, el reconstruido tras la guerra civil de 1936. La catedral es otro de los elementos simbólicos de la ciudad. Asoma el pináculo del campanario, tal y como ocurre en la simulación. Se ubica en la ladera sur y sólo se ve la parte más saliente. Campanario ubicado exactamente en el centro del cuadro y bajo la vertical de uno de los elementos más simbólicos y religiosos del cuadro.

En el centro del cuadro se encuentra el Hospital de San Juan Bautista o de Tavera. La fachada del Hospital ha sido girada $180^{\circ}$ grados para que aparezca frente al observador. La puerta principal del hospital mira, en verdad, hacia la ciudad de Toledo y por tanto se enfrenta a la puerta de Bisagra. Se percibe también en la vista que hizo de la ciudad Wyngaerde, donde en construcción, 
todavía no se ha terminado su característica cúpula. El Greco intencionadamente lo rota, lo mueve levemente y lo reescala, aumentándolo de tamaño con respecto a todos los elementos circundantes. Se trata del único elemento de la fisonomía de Toledo que se aproxima más a la imagen simbólica de la ciudad que a la real. Se trata de la clave de bóveda que engarza las dos imágenes figurativas de la ciudad con el trasfondo del encargo del cuadro.

A la precisión en las localizaciones espaciales hay que añadir la información que la obra aporta sobre sus coordenadas temporales. Se trata de una estampa de una mañana veraniega de la ciudad. Se percibe por un lado, la posición de las sombras, en por ejemplo las ventanas de El Alcázar. Por otro, frente a la puerta de Bisagra aparecen elementos cotidianos de la siega, propia de períodos estivales.

\section{Plano DE TOledo}

La visión del plano a través del lienzo es un poco difusa, más aún para un análisis detallado. En 1967 se recreó dicho mapa, cuya copia se encuentra disponible en la web ${ }^{16}$. Esta copia es la utilizada para la georreferenciación.

El mapa tiene orientación sur, equivalente a la vista de la ciudad del cuadro. Este hecho agiliza la lectura visual entre la vista oblicua de la ciudad y el mapa. Implica que el río quede en la parte superior del mapa; hecho muy distinto a los mapas que estamos hoy acostumbrados con la orientación Norte. Cuenta con múltiples inscripciones entre las que destacan las centradas en la georreferenciación. Aparecen a izquierda y derecha los textos «Levante y Poniente» respectivamente. Hacen referencia a los vientos. En la parte superior, por encima de la margen del río Tajo aparece Ostro que define a los vientos del Sur. Así mismo aparece una escala gráfica. Denota una búsqueda por la geometría y la exactitud más propia de la emergente cartografía renacentista que de mapas medievales. La escala gráfica, y no numérica facilita la posibilidad de que el mapa haya sido reescalado desde otro documento. En el año 2009, se analizó la obra mediante reflectografía infrarroja. Sacó a relucir una cuadrícula debajo de las pinturas, la cual podemos asociar al método de transposición también empleado por Wyngaerde en sus vistas ${ }^{17}$. En otra investigación

16 http://hemeroteca.abc.es/nav/Navigate.exe/hemeroteca/madrid/abc/1967/08/12/047.html (Verificada: 22/9/2015).

17 Garrido, C. (2009): "Vista y plano de Toledo del museo del Greco". Cuadernos de Arte, 40 , pp. 53-62. 
sobre el atlas de El Escorial, existen coincidencias entre un listado de nombres de las visuales de las iglesias y edificios de Toledo, y los que aparecen en este mapa $^{18}$. En el atlas de El Escorial ya no se conserva este mapa. El papel donde se realizó el mapa de Toledo fue reutilizado y sólo es posible admirarlo a través del cuadro del Greco. Este hecho le dota de un gran valor histórico y desde luego cartográfico. Bien pudiera ser copiado del Atlas e incluso elaborado por él mismo y/o su hijo. Lo que es innegable es la preocupación por la geometría y exactitud de la representación en esta parte de la obra.

FIGURA 3

VISTA GEORREFERENCIADA DEL MAPA DE TOLEDO SOBRE GOOGLE EARTH

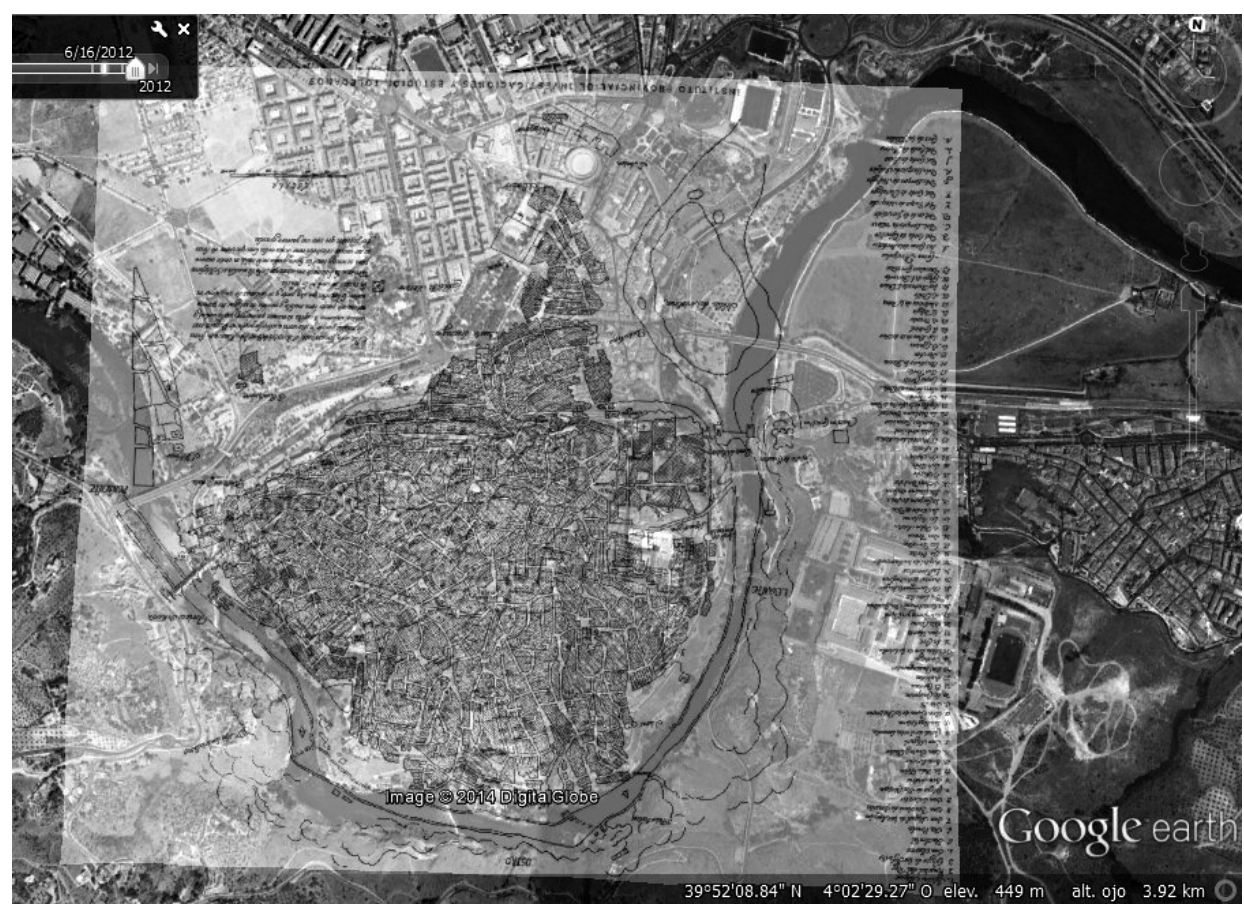

Fuente: vista de Google Earth. Elaboración Propia.

18 Crespo, A. (2005): "Un mapa olvidado: el atlas de El Escorial". Revista Catastro, 12, pp. 59-89.

Estudios Geográficos, Vol. LXXVI, 279, pp. 751-760, julio-diciembre 2015

ISSN: 0014-1496, eISSN: 1988-8546 
Este hecho se constata a través de la georreferenciación del mapa realizada con el programa GVSIG $^{19}$ y la base cartográfica Cartociudad ${ }^{20}$ del Instituto Geográfico Nacional (IGN) de la ciudad de Toledo. Se ha procedido a asignar 7 puntos distribuidos a lo largo de la imagen para realizar una transformación afín aceptando un error medio cuadrático de 0,81 . El resultado se exporto a formato KML para poderlo visualizar en Google Earth ${ }^{21}$.

Se aprecia un ajuste casi perfecto en todo el perímetro del río y en la parte norte de la ciudad con la muralla. Se aprecia también como ya hace 400 años el caso histórico de Toledo se encontraba prácticamente consolidado y es probable que las zonas que más cambios habían sufrido fueran las zonas próximas al Alcázar o las recientes actuaciones urbanísticas de Zocodover y el Hospital de Santa Cruz. Consecuencia de esa falta de espacio intramuros es el Hospital de afuera, el cual se ajusta perfectamente en planta, a diferencia de la posición icónica e imaginaria de la vista.

Finalmente, en el borde del mapa, aparecen toda una serie de inscripciones que corresponden con lugares representados en la cartografía. Dicho estudio reconoce 69 edificios religiosos (parroquias, conventos, hospitales,...) ordenados por criterios topográficos y reseñados a un lado del mapa ${ }^{22}$. Es un listado enumerativo que localiza y complementa la vista y plano a semejanza de los listados de repertorios de lugares o bien como las «Relaciones Topográficas» de Felipe II.

\section{CONCLUSIONES}

Existen múltiples lecturas en este cuadro: por un lado el simbolismo religioso a través de la imagen de la virgen descendiendo para poner la casulla a San Ildefonso patrón de la ciudad. Por otro, el simbolismo económico de la ciudad a través de su río, elemento geográfico central en la fisonomía y evolución de la ciudad. En tercer lugar existe una importante verosimilitud y exactitud de la representación gráfica, cartográfica y textual de Toledo, plasmando la concepción ptolemaica sobre descripción correcta de la superficie terrestre. Esta concepción alumbra también en los trabajos encargados por Felipe II

\footnotetext{
19 http://www.gvsig.org/es (Verificada: 22/9/2015)

$20 \mathrm{http} / / /$ www.cartociudad.es/portal/ (Verificada: 22/9/2015).

${ }^{21} \mathrm{http}: / /$ www.google.es/intl/es/earth/index.html (Verificada: 22/9/2015).

22 Porres Martín, Cleto, J. (1967): "Plano de Toledo" de Domenico Theotocopuli El Greco. Toledo, Instituto de Investigaciones y Estudios Toledanos, Diputación de Toledo.
} 
para el conocimiento exhaustivo de sus territorios a través de vistas, mapas y listados o repertorios. Se produce un cierto mimetismo en las formas de analizar y catalogar el territorio. El Greco es capaz de presentar un exhaustivo análisis, desde múltiples formas y perspectivas, de la ciudad de Toledo a semejanza de las formas imperantes en el conocimiento del territorio en el Renacimiento español.

Juan Antonio García González Universidad de Castilla-La Mancha 